\title{
Movimentações envolvendo Indígenas Kaingang e imigrantes alemães em territórios da Bacia Hidrográfica do Caí
}

\author{
Luís Fernando da Silva Laroque \\ Universidade do Vale do Taquari - RS - Brasil \\ Neli Teresinha Galarce Machado \\ Universidade do Vale do Taquari - RS - Brasil \\ Moisés Ilair Blum Vedoy \\ Universidade do Vale do Taquari - RS - Brasil
}

\begin{abstract}
Resumo
O presente trabalho objetiva analisar o avanço da frente de expansão do Estado Nacional brasileiro e as movimentações envolvendo indígenas Kaingang e imigrantes alemães em territórios da Bacia Hidrográfica do Caí. O avanço da frente de expansão do Estado Nacional brasileiro em direção ao planalto do Rio Grande do Sul a partir da ocupação de territórios da Bacia Hidrográfica do Caí decorreu da instalação de imigrantes alemães. Este processo acarretou uma fronteira interétnica entre indígenas Kaingang e imigrantes alemães, intensificando relações de aliança e de conflito entre ambos os grupos. Considera-se que o território e suas distintas concepções foi um fator determinante na relação entre indígenas e imigrantes, tanto no âmbito dos conflitos como das movimentações. Por tratar-se de um espaço de disputa entre as duas etnias, a gradual perda do território motivou os Kaingang a intensificarem suas movimentações e investidas guerreiras contra o invasor, seguindo a lógica cultural nativa. Aos imigrantes coube concretizar as movimentações estabelecidas pelo governo.
\end{abstract}

Palavras-Chave: Imigrantes alemães. Indígenas Kaingang. Movimentações territoriais. Bacia Hidrográfica do Caí.

\footnotetext{
1 Trabalho vinculado aos projetos de pesquisa, "Arqueologia, História Ambiental e Etno-história do RS" e "Sociedades Indígenas Kaingang em territórios da Bacia Hidrográfica Taquari-Antas" e conta com auxílio financeiro do CNPq, Fapergs e Univates. Um resumo e apresentação preliminar do trabalho foi apresentado no I Seminário Internacional - Migrações e Direitos Humanos ocorrido nos dias 18 e 19 de maio de 2016, na Univates, cidade Lajeado/Rio Grande do Sul.
} 


\title{
Movements involving Kaingang Indians and German immigrants in territories of Caí hydrographic Basin
}

\begin{abstract}
This paper aims at analyzing the advance of the agricultural frontier of the Brazilian national State and the spatial movements of Kaingang Indians and German immigrants in Caí hydrographic basin. The Brazilian national State advance towards the plateau of the state of Rio Grande do Sul was accomplished through the settlement of German immigrants in the Caí hydrographic basin. This process built an interethnic frontier between the Kaingang people and German immigrants, intensifying relations of alliance and conflict between both groups. We consider that the territory and its distinct conceptions were a decisive aspect involving the relationship between Indians and immigrants, both on a matter of conflict and displacement. As if it was a disputed space between two ethnic groups, the gradual loss of territory implied that the Kaingang intensified their movements and belligerent charges against the invaders, following their own native cultural logic; concerning to immigrants, they had to consolidate the movements established and wanted by the Government. Keywords: German immigrants. Kaingang Indians. Territorial movements. Caí hydrographic basin.
\end{abstract}

\section{Movimientos involucrando a Indígenas Kaingang e Inmigrantes Alemanes en territorios de la cuenca hidrográfica del Caí}

\section{Resumen}

El presente trabajo tiene como objetivo analizar el avance del frente de expansión del Estado Nacional brasileño y los movimientos involucrando a indígenas Kaingang e inmigrantes alemanes en territorios de la Cuenca del Caí. El avance del frente de expansión del Estado Nacional brasileño hacia la meseta de Rio Grande do Sul a partir de la ocupación de territorios de la Cuenca Hidrográfica del Caí, se hizo a través de la instalación de inmigrantes alemanes. Este proceso produjo una frontera interétnica entre indígenas Kaingang e inmigrantes alemanes intensificando relaciones de alianza y conflicto entre ambos grupos. Se considera que el territorio y sus distintas concepciones fue un factor determinante en la relación entre indígenas e inmigrantes, tanto en el ámbito de los conflictos como de los movimientos. Por tratarse de un espacio de disputa entre las dos etnias, la gradual pérdida del territorio hizo que los Kaingang intensificaran sus movimientos e invertidas guerreras frente al invasor siguiendo la lógica cultural nativa, ya a los inmigrantes cupo concretar los movimientos establecidos por el gobierno.

Palabras-Clave: Inmigrantes alemanes. Indígenas Kaingang. Movimientos territoriales. Cuenca del Caí.

\section{Introdução}

A maioria das relações interétnicas é estabelecida pelo contato entre as diferentes culturas em determinado território. Essas relações expõem as concepções conflitantes de ambas as etnias acerca desse território. No Rio Grande do Sul do século XIX, não se fugiu à regra, sobretudo, com a chegada do imigrante alemão para ocupar territórios indígenas considerados "vazios" pelo Império Brasileiro e governantes da Província de São Pedro do Rio Grande do Sul. O fio condutor do estudo debruça-se sobre o contato interétnico entre Kaingang e imigrantes alemães em territórios entre as Bacias Hidrográficas do Caí e do Taquari-Antas, ao longo do século XIX, com o objetivo de analisar o avanço da frente de expansão do Estado 
Nacional brasileiro e as movimentações envolvendo indígenas Kaingang e imigrantes alemães em territórios da Bacia Hidrográfica do Caí.

A metodologia baseia-se em estudos de Gonçalves, Meirelles (2004) e de Mezzaroba, Monteiro (2006), no que se refere à abordagem qualitativa, bem como, nos fenômenos relacionados aos processos de investigação científica. Os procedimentos metodológicos consistem na revisão bibliográfica com foco nos indígenas Kaingang e na imigração alemã e no levantamento e análise de fontes documentais que consistem em relatos de viajante e relatórios disponíveis no Arquivo Histórico do Rio Grande do Sul. Salienta-se que tanto os dados bibliográficos como os documentais foram tratados considerando a etno-história, abordagem que, segundo Cavalcanti (2011), possibilita tratar de forma interdisciplinar as fontes com vistas a reconstituir momentos de historicidades indígenas. Do ponto de vista teórico para a análise das fontes, foram utilizados os estudos de Barth ([1969] 2000), Geertz (1978), Clastres ([1980] 2014), Brandão (1986) e Martins (1996 e 1997).

\section{A frente de expansão em direção ao planalto: o estabelecimento das Colônias de imigrantes alemães em territórios da Bacia Hidrográfica do Caí}

O processo de imigração alemã, conforme Roche (1969) e Cunha (2006), pode ser compreendido como um projeto de povoamento ao longo do século XIX, já iniciado antes de 1822, data da independência oficial do Brasil de Portugal. No início do século XIX, já se apontava para a instalação de europeus em solo brasileiro, por meio de decreto de $\mathrm{D}$. João $\mathrm{VI}$, em 1808 , que permitia a concessão de sesmarias a estrangeiros, desde que já instalados no Brasil, dando assim o impulso inicial para as políticas imigratórias que viriam a acontecer ao longo do século XIX. A instalação de suíços em 1819 na recém-criada Colônia de Nova Friburgo no Rio de Janeiro, por exemplo, dava início à tradição de ajuda oficial aos estrangeiros.

Por outro lado, no que se refere aos povos indígenas, vale apontar a política adotada pelo mesmo D. João VI, que, por meio de Cartas Régias ${ }^{2}$, autorizava a "guerra aos bugres". Visando à intensificação da ocupação territorial, dispunha os tradicionais territórios indígenas para a imigração europeia no sul do Brasil. Assim, o discurso "civilização versus barbárie" saía das palavras e do pensamento para a prática, inaugurando, inclusive, uma jurisdição que autorizava a qualquer um capturar e prender a população indígena. "Estas leis, recorrendo ao velho discurso de que os índios eram obstáculos para o avanço do progresso e da civilização, retomaram as guerras a aqueles que [...], passaram a ser tratados como prisioneiros de guerra" (LAROQUE, 2000, p.28).

No Rio Grande do Sul, a imigração alemã teve início em 1824, com a oferta de atrativos e vantagens relativos a dinheiro e posse de terras aos imigrantes por parte do governo brasileiro. Apesar de contraditória, para o governo, "essa empresa, que ia contra a estrutura social e contra a concepção socioeconômica herdada do período colonial, tinha caráter revolucionário" (ROCHE, 1969, p.93). Ainda que o governo Imperial objetivasse criar uma classe social intermediária entre os grandes latifundiários e os escravos negros, nesta estruturação, o indígena, tradicional ocupante destes espaços que viriam a ser colonizados por imigrantes alemães, não era considerado como sujeito participativo deste projeto ocupacional.

2 Documento pelo qual um monarca exerce o seu poder, delegando ordens a autoridades menores. 
Em síntese, as políticas expropriatórias do Estado Nacional brasileiro no século XIX davam seguimento às propostas do Brasil Colônia, que, na maioria dos casos, selavam o destino de muitas populações indígenas, conforme visto nas Cartas Régias, que incentivavam as frentes de expansão em busca de abastecimento e de interesses econômicos da metrópole portuguesa. No século XIX, surgiu a categorização das populações indígenas, que foram classificadas como "domésticos" ou "mansos" e os "bravos", com o objetivo de esquematizar as ações em relação a eles. Às duas primeiras, atribuiu-se tratamento "civilizatório", de inclusão na sociedade, por meio da religião e dos costumes. "Aos considerados 'bravos', não restava outra solução a não ser exterminá-los para que não impedissem o avanço da civilização" (BRINGMANN, 2010, p.62).

Com o intuito de abrir espaço para esta nova empreitada, que era a colonização e a imigração europeia, o governo usava dois artifícios: aos Kaingang, impunham-se a força e a brutalidade coercitiva; aos imigrantes, ofereciam-se as terras devolutas, que eram territórios tradicionais ocupados pelos indígenas.

Em se tratando da colonização alemã no século XIX, de acordo com Roche (1969), Lando e Barros (1996), é possível dividir este processo imigratório em dois momentos: O primeiro, que vai de 1824 até 1844 , pode ser caracterizado pela ordem governamental do Império e pela organização administrativa para a instalação dos imigrantes. O segundo momento, iniciado em 1844, ano em que se retoma a imigração, estende-se até a década de 1860. Caracteriza-se pelo incentivo às colônias particulares e pelo envolvimento do governo das províncias do sul.

Entre os atrativos do governo imperial brasileiro para a imigração alemã, temos a oferta de colônias, constituídas de porções territoriais de terras devolutas que eram demarcadas. Contudo, a organização destas primeiras ocupações passou por um período conturbado, pois a Constituição Imperial, embora a propaganda acenasse, não previa a concessão de nacionalidade imediata; portanto, não se conseguia cumprir o prometido. Salientam-se, também, já nos primeiros meses de 1824, além da dura realidade da floresta, problemas relativos à infraestrutura prometida, considerando que "[...] a experiência de recrutamento de milhares de alemães na Europa e de instalação deles no sul do Brasil procedeu-se em um ritmo mais intenso do que a capacidade administrativa das autoridades imperiais" (RÜCKERT, 2013, p. 208).

Em 1824, concretizou-se a primeira experiência de povoamento. Os imigrantes foram instalados na antiga Feitoria do Linho Cânhamo, pertencente à jurisdição do município de Porto Alegre, que, posteriormente, passaria a constituir a antiga Colônia de São Leopoldo. Portanto, movidos pela promessa de concessão de terras, ferramentas e subsídios, os imigrantes alemães chegam ao Brasil. Segundo Roche (1969), ao todo, 5350 imigrantes alemães estabelecem-se no Rio Grande do Sul, entre 1824 e 1830. Grande parte destes imigrantes foi instalada de imediato na colônia de São Leopoldo, visto que a curta distância até Porto Alegre e as estruturas de São Leopoldo atraíam os imigrantes a permanecerem nos seus entornos.

Um dos encarregados de trazer novos soldados e colonos era o major Von Shäeffer. No contexto emancipatório, em 1822, ele foi enviado para os reinos germânicos com o intuito de buscar o "reconhecimento da independência do Brasil e organizar a contratação de colonos soldados que deveriam povoar as regiões de fronteiras do sul do país" (ANDRÄ apud CUNHA, 2006, p.282). 
Entre os objetivos da colonização, como visto anteriormente, estava a formação de um grande exército que fosse capaz de defender a ocupação territorial do Estado Nacional Brasileiro, a exemplo do que foram os Brummer3, pois "eram cada vez mais visíveis as dificuldades de controle das fronteiras e, consequentemente, da própria hegemonia do Império" (BRINGMANN, 2010, p.52).

Logo em seguida ao estabelecimento destes colonizadores, começaram a aparecer os primeiros impasses. Segundo Roche (1969), o governo passou a ter problemas em relação à instalação e à distribuição de terras gratuitas, pois gerava altos gastos, o que munia a argumentação da oposição à imigração, levando à interrupção da imigração no ano de 1830. Conforme Seyferth (2002, p. 119), a "[...] primeira fase da colonização encerrou-se em 1830, quando a oposição parlamentar aprovou uma lei que impedia gastos com a imigração - o que, na prática, inviabilizou o agenciamento, pois não existia um fluxo espontâneo para o Brasil”.

A estes problemas somava-se a dificuldade do europeu com o manejo da terra, pois a geografia destes espaços nada tinha a ver com o solo europeu. Nesse sentido, acentua-se a apropriação pelos novos colonos, de antigas técnicas indígenas em relação ao uso da terra, no caso, a derrubada da mata e a queimada. Conforme aponta Bublitz (2008, p.327), "tratava-se do resultado da apropriação e da adaptação de uma tecnologia indígena, que a partir de então passava a ser utilizada em grande escala e de forma agressiva, implicando alterações ecológicas drásticas". Houve também os primeiros conflitos com os Kaingang no entorno da Colônia de São Leopoldo.

De acordo com Roche (1969), administrativamente, estas colônias respeitavam as leis da colonização, que foram sendo modificadas ao longo das décadas seguintes, conforme os interesses das políticas do Império. Entre os cargos estava o de inspetor, que se encarregava da distribuição dos materiais fornecidos pelo Estado e da formulação de medidas repressivas em relação a crimes cometidos na colônia, aplicadas por suboficiais dos batalhões alemães. Abaixo dele estava o Diretor da colônia, responsável por intermediar as relações entre a colônia e o Estado.

Coube também ao inspetor organizar qual seria a principal fonte econômica das colônias, no caso, a agricultura, que, posteriormente, se expandiria para territórios localizados na Bacia Hidrográfica do Caí. Assim, foram escolhidas áreas com melhor acesso e com maior possibilidade de transporte até Porto Alegre, haja vista que o comércio precisava ser incentivado. "Estimulado inicialmente pelo excedente agrícola dos colonos e pela proximidade da capital da Província, o comércio gerou lucros que foram parcialmente investidos na produção artesanal de São Leopoldo" (RÜCKERT, 2013, p.214).

Este primeiro momento de imigração foi interrompido pela eclosão da Guerra Farroupilha (1835-1845), que manteve a Província de São Pedro do Rio Grande do Sul como palco de guerra durante dez anos. Segundo Farinati (2007, p. 70), o "[...] Brasil vivia o processo instável de construção e de consolidação do Estado Imperial”. Ainda, em relação à interrupção da imigração no período em questão, temos o seguinte:

não desapareceu, contudo, a ideia de que era necessário promover a imigração para desenvolver as regiões remotas do país e precaver a economia do Estado diante da inevitável crise a ser provocada, cedo ou tarde, pela suspensão definitiva do tráfico de escravos. As vias para a

3 Mercenários alemães que vinham para o Brasil compor as tropas imperiais. 
promoção da imigração e colonização é que deveriam ser outras que não as que onerassem ainda mais as já comprometidas finanças do Império (CUNHA, 2006, p.282).

Nesse sentido, a segunda fase, que se estende de meados da década de 1840 até, grosso modo, os últimos anos da década de 1860, caracteriza-se pela participação provincial do Rio Grande do Sul e da inciativa privada para atrair a vinda de novos imigrantes, ou mesmo a imigração espontânea. "Com o término da guerra civil e com o restabelecimento da ordem, já em 1844 entraram em São Leopoldo os primeiros imigrantes depois do encerramento da fase inicial da colonização" (LANDO; BARROS, 1996, p.28). Em relação ao final da década de 1840, destaca-se:

\begin{abstract}
neste período, o governo não possuía um organismo que administrasse a entrada e a localização dos novos imigrantes em seus lotes e, em 1846, os colonos não podendo contatar com outras terras a não ser as do sertão, longe das picadas abertas e sem demarcação, ficaram entregues à própria sorte e já não podiam contar com os lotes demarcados (NONNENMACHER, 2000, p.13).
\end{abstract}

Esta falta de organização, quando reiniciou o processo da imigração, evidencia o caráter expansionista e pioneiro que o governo procurava internalizar no imigrante, no sentido de adentrar e desbravar uma terra que para eles era inóspita. Esse projeto levou o governo imperial a repassar a responsabilidade da empresa aos chefes de Província, através da "Lei de $n^{\circ} 514$, de 1848 , que dava às províncias coparticipação numa tarefa que até esta época pertencia exclusivamente ao Governo Imperial" (LANDO; BARROS, 1996, p. 29).

Frente a isso, as províncias, como é o caso do Rio Grande do Sul, adotaram medidas para facilitar a chegada de novos imigrantes por meio de contratos de companhias privadas, estabelecidos pela "lei Provincial 304 de 1854, segundo a qual as terras não seriam mais doadas, mas vendidas aos colonos" (LANDO; BARROS, 1996, p.30). Salienta-se que a imigração foi um dos elementos da frente de expansão do Estado Nacional brasileiro no século XIX, que, somada a mecanismos como abertura de estradas, as companhias de extermínio dos Kaingang e o estabelecimento dos grandes aldeamentos incidiram diretamente sobre os tradicionais territórios Kaingang na Bacia Hidrográfica do Caí.

No século XIX, a viabilização do projeto colonizador de expansão, inicialmente, efetiva-se com o estabelecimento de sesmarias em territórios localizados na Bacia Hidrográfica Taquari-Antas. No decorrer do mesmo período, com a imigração, ocorre também o estabelecimento de colônias em territórios localizados entre a Bacia Hidrográfica do Caí e a do Taquari em direção ao planalto. Se até então a empresa colonizadora dependia da mão de obra escrava, com a chegada dos imigrantes alemães, este cenário foi modificado. 
Vale salientar, embora não abordado neste estudo, que a continuidade deste empreendimento segue com a frente pioneira, compreendida como um processo baseado no mercado moderno e liberal. Em relação à frente pioneira, Martins aponta: [...] quando os geógrafos falavam de frente pioneira estavam falando de uma das faces da reprodução ampliada do capital: a sua reprodução extensiva e territorial, essencialmente mediante a conversão da terra em mercadoria e, portanto, em renda capitalizada, como indicava e indica a proliferação de companhias de terras e negócios imobiliários nas áreas de fronteira em que a expansão assume essa forma. Nesse sentido, estavam falando de uma das dimensões da reprodução capitalista do capital (MARTINS, 1996, p.30).

Portanto, retomando a frente de expansão no século XIX pelo Império brasileiro, considerando interesses econômicos, formaram-se as chamadas colônias particulares, em direção ao planalto, conforme mapa (figura 1).

Figura 1 - Mapa indicando Colônias de Imigração Oficiais e Particulares.

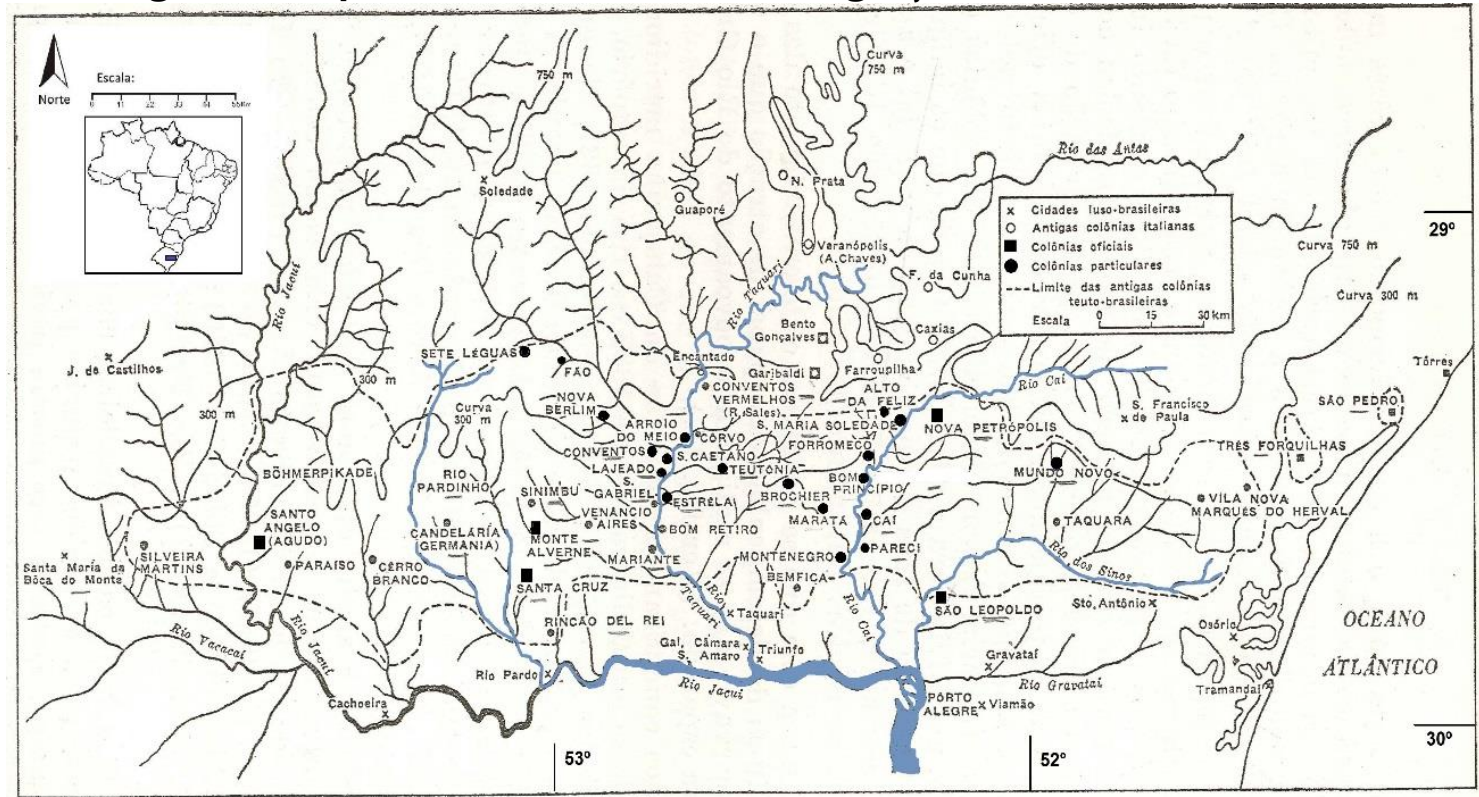

Fonte: Adaptação do mapa de Roche (1969).

Este projeto tornou-se a principal forma de instalação de imigrantes alemães ao longo da Bacia Hidrográfica do Caí no decorrer da década de 1850, conforme citase a seguir:

Nova Petrópolis, fundada em 1858; Santa Cruz, em 1847; Santo Ângelo, em 1855; Montalverne, em 1859; Estrela, em 1856; São Lourenço, em 1858; Mundo Novo, em 1846; Porto das Laranjeiras, em 1840; Santa Maria da Soledade, em 1857 (LANDO; BARROS, 1996, p.30).

Também é possível visualizar no mapa que a colonização alemã espalhou-se rapidamente ao longo da Bacia Hidrográfica do Caí a partir da colônia de São Leopoldo, movimentando-se em direção ao planalto e à Bacia hidrográfica do Taquari-Antas. No decorrer deste processo, intensifica-se o contato interétnico entre os Kaingang e os imigrantes alemães ao longo das décadas de 1850 e 1860, que, junto com os grandes aldeamentos, objetivavam retirar os Kaingang de suas terras. 
Observando o mapa anterior, visualiza-se o estabelecimento das chamadas colônias oficiais, bem como, a expansão das colônias particulares. A título de exemplo, chamamos atenção para a Colônia Santa Maria da Soledade, localizada na margem direita da Bacia do Caí em direção ao norte do território, a qual foi fomentada pela Sociedade Montravel, Silveira e Cia. Esta colônia foi instalada num espaço estratégico para a Província, pois se localizava entre as áreas mais altas do planalto e territórios das bacias hidrográficas mais baixas. A mesma importância era atribuída a este espaço pelos Kaingang, pois, possivelmente, tratava-se de um espaço de percurso em direção às terras mais baixas.

Conforme Roche (1969) e Lando e Barros (1996), a partir da necessidade de reorganização das políticas imigratórias, uma série de leis foi aprovada. Conforme já referido, entre as leis que atingiram diretamente a organização da colonização alemã nesta segunda fase, temos a Lei Geral $n^{\circ} 514$, de outubro de 1848 , que estabelece a destinação, para as províncias, de terras exclusivas para a colonização do Império. Nesse sentido, a viajante belga Maria van Langendonck ([1862] 2002, p. 31) faz o seguinte registro em seu diário, em relação à Sociedade Montravel: "Dois dias depois de nossa chegada, Léon, meu filho mais velho, deixou Porto Alegre para ir escolher o sítio de uma colônia nas terras concedidas ao Conde de Montravel pelo governo brasileiro". Concedendo indiretamente a terra ao colono, cabia ao beneficiado desbravar e explorar as terras dentro de um prazo de cinco anos. Tratava-se de uma forma de incentivo à agricultura extensiva.

Seguiu-se a Lei de Terras de 1850, segundo a qual o título de posse dependia da compra da terra, dando assim fim às concessões. "A Lei de Terras era uma medida que procurava, por um lado, dificultar o livre acesso à terra e, por outro, obrigar os imigrantes que chegassem ao país a empregar sua força de trabalho nas grandes lavouras" (CUNHA, 2006, p.290). No Rio Grande do Sul, a lei possibilitou que alguns proprietários particulares, comerciantes de terras, loteassem e vendessem grandes quantidades de terras para a colonização particular. No século XIX, conforme Rodrigues (2012), a questão indígena tornou-se um problema fundiário para a expansão da modernização da sociedade nacional. Em relação à lei de Terras de 1850 salienta:

nota-se, então, que a sociedade nacional encontrava, na própria Lei de Terras, a regulamentação necessária para o confisco das terras habitadas pelos indígenas, o direito às terras que habitavam, devido a uma suposta assimilação (RODRIGUES, 2012, p.62).

Nesse contexto, a Província, na década de 1850, considerou fundamental a colonização, visto que a mão de obra escrava estava em crise. Segundo a visão e discursos da época, "o escravo representava uma força negativa ao espírito de expansão do sistema capitalista"; portanto, vislumbrava-se na colonização e na agricultura um futuro promissor (LANDO; BARROS, 1996, p.17). Ofereciam-se indenizações de viagem aos colonos, bem como, estabeleceu-se uma base regulamentar através da Lei Provincial ${ }^{4}$ de 1851 e da Lei de 1854 e do regulamento de 1855. Essa regulamentação, em linhas gerais, pouco mudou em relação às leis

4 Leis que versam sobre os estatutos internos da Província de São Pedro do Rio Grande do Sul no século XIX. 
anteriores, mas promulgava-se, de fato, o estatuto provincial à colonização, ficando definido o seguinte:

o desbravamento e a exploração das terras são, com o pagamento de seu valor, as condições necessárias à plena aquisição da propriedade pelo colono, que deve residir no lote comprado e cultivá-lo no prazo máximo de dois anos, sem que as terras reverterão para o domínio provincial (ROCHE, 1969, p.102).

A administração provincial, além de tomar medidas em relação ao alojamento e à manutenção destes imigrantes, buscou incorporar à administração um número maior de agentes administrativos para mediarem as relações entre as colônias e o governo, no caso, os cargos de diretor e de tutor, além de agentes intérpretes e de um inspetor geral. Esses cargos dependiam das políticas orçamentárias do governo e da opinião da Assembleia Provincial.

Observa-se também que as legislações, tanto as do Governo Imperial quanto as do provincial, incentivavam as colônias particulares que loteassem as terras em partes menores, visando desbravar ou mesmo incorporar os ditos espaços "vazios" onde se localizavam as terras devolutas, espaço no qual se aplicaria uma agricultura extensiva, com o objetivo de escoar a produção do planalto através da Bacia Hidrográfica do Caí até Porto Alegre.

Esta ocupação concretizava-se através de contratos particulares, assinados entre o governo provincial e os donos de empresas colonizadoras. A título de exemplo, cita-se Pedro Kleudgen, responsável, a partir de 1851, por "introduzir dois mil imigrantes, num prazo de dois anos, na Colônia de Santa Cruz" (CUNHA, 2006, p.285). A Sociedade Montravel, a partir de 1856, foi responsável por introduzir imigrantes na Colônia Santa Maria da Soledade. Também, Julius Knorr, agente da Companhia Hamburgo-Brasileira, "assina em dezembro de 1859, um contrato com a firma Steinmann para a introdução, dentro de um ano, de 500 imigrantes entre as idades de 2 a 45 anos" (ROCHE, 1969, p.107).

Acompanhando o longo curso da Bacia Hidrográfica do Caí, a imigração alemã seguiu em direção ao norte, a partir da chamada "antiga colônia" São Leopoldo na Bacia Hidrográfica do Sinos, chegando, em 1856, à Colônia de Santa Maria da Soledade, que incorpora os atuais municípios de São Sebastião do Caí, São Vendelino, Feliz, Carlos Barbosa, além de outros, conforme o mapa (Figura 1), onde é possível visualizar as colônias oficiais e as particulares.

Fato é que a maioria destes contratos não era cumprida nem em relação ao número de imigrantes, nem em relação às ofertas aos imigrantes, que, muitas vezes, conforme referido, estavam à mercê da própria sorte. Segundo Bublitz (2008), ao se defrontar com a floresta, o imigrante não reconhecia qualquer semelhança com a paisagem idílica e idealizada dos europeus, mas defrontava-se com um imaginário medieval de medo em relação à floresta desconhecida. Nestas florestas, encontravam tigres, cobras e onças, além da ameaça que representavam os indígenas Kaingang. "No início, mais do que qualquer outro sentimento, a mata suscitava medo. Não apenas devido à força da vegetação, por si só intimidadora, mas também devido aos povos e aos animais que a habitavam" (BUBLITZ, 2008, p. 237). Este medo também é explicitado no diário da viajante belga Maria van Langendonck ([1862] 2002), envolvendo sua estada na Colônia Santa Maria da Soledade: "no momento de nos separarmos dessa boa gente, eles perguntaram aonde íamos: 
quando souberam que íamos às altas terras recém-concedidas, menearam a cabeça" (LANGENDONCK, [1862] 2002, p.36).

A instalação dos imigrantes alemães na mata no limiar da frente de expansão do Estado Nacional brasileiro trouxe inevitáveis interações a partir da formação de uma fronteira interétnica entre esses imigrantes e os indígenas Kaingang. Destaca-se que a maioria dessas interações eram conflituosas, visto que a subsistência e a organização social dos Kaingang dependiam dos territórios nos quais os imigrantes são vistos pelos indígenas como estranhos.

A usurpação e o uso predatório com que os imigrantes alemães se lançaram sobre as matas e os territórios Kaingang foi sob a tutela do governo provincial e de forma arbitrária no que tange às políticas imigratórias e indigenistas do século XIX. A efetivação do projeto que referenciava o território em questão como terras devolutas ou espaços "vazios" contribuiu para que o contato entre colonos e Kaingang não fosse, de maneira alguma, amistoso.

Podemos observar nesta atitude do governo e das companhias colonizadoras, um aparente engodo aos colonos e também uma clara desconsideração ao sujeito índio, ao menosprezar sua capacidade de defesa do território (BRINGMANN, 2010, p.58).

A partir de então, o uso da força foi uma constante de ambos os lados, em primeiro lugar, por parte do governo para expulsar os Kaingang de seu território. Em seguida, a guerra por parte dos indígenas contra os imigrantes, até então o mecanismo de defesa mais conhecido por ambas as sociedades. Estes embates endureceram ainda mais as políticas indigenistas em relação ao Kaingang. Foram aplicados diversos mecanismos com o objetivo de tirar os Kaingang do seu tradicional território e de afastar o medo que crescia entre os colonos. Entre estes mecanismos destaca-se a Companhia de Pedestres, que, desde o século XVIII, era utilizada como destacamentos oficiais de policiamento. No século XIX, já era um mecanismo sistematizado, cuja função era adentrar os sertões para prender ou mesmo matar os indígenas, que, segundo o governo, causavam ameaças e problemas. No território da Bacia Hidrográfica do Caí, é possível destacar dois aquartelamentos, "de modo que um ficasse na parte externa da Picada Feliz, junto ao Arroio Lajeado, e outro, na parte externa inferior da mesma picada sobre o Passo Esperança" (NONNENMACHER, 2000, p.18).

Ao mesmo tempo em que os Kaingang eram retirados do seu território para a continuidade do projeto de instalação de imigrantes, eram forçados a adequar-se ao novo modelo cultural, ao qual não estavam habituados. Neste momento também se enraíza o discurso do índio "selvagem" e "vagabundo". Conforme Becker (1995) e Laroque (2000), com a vinda do imigrante alemão, os Kaingang vão, paulatinamente, perdendo o seu principal meio de sobrevivência, no caso, a caça e a pesca, e passaram a viver de auxílios recebidos do governo da Província, que consistia de roupas, alimentos e utensílios.

Ainda, a abertura de estradas, junto com os aldeamentos, foi, talvez, um dos principais mecanismos que possibilitaram o avanço do Estado Nacional brasileiro em direção ao Planalto. Com o objetivo de interligar a colônia de São Leopoldo ao Planalto, em busca de novas áreas a serem colonizadas, o governo deu prioridade à estrada que ia de "São Leopoldo e seguia pela Picada Feliz, indo em direção a Taquari, 
seguindo para Cima da Serra, nos Campos de Vacaria e cortando a estrada que vinha das Missões para Lages e Santa Catarina" (NONNENMACHER, 2000, p.26).

Outro mecanismo utilizado foi o da Companhia de Bugreiros no Rio Grande do Sul, que, semelhante ao ocorrido em Santa Catarina e São Paulo, conforme Nötzold e Bringmann (2010), era constituído por homens armados, sem ligação com órgão público. Ou seja, eram particulares que faziam vistorias nas matas em busca de pares de orelhas aos moldes dos escalpos norte-americanos, ou manifestavam outras atitudes hostis e agressivas em relação aos indígenas, "contando, muitas vezes, com a ajuda de nativos pertencentes a facções inimigas das tribos procuradas" (LAROQUE, 2000, p.64).

Estes particulares eram uma espécie de mercenários, que recebiam pagamento de acordo com o número de pares de orelhas que entregassem ao governo da província. Esse fato nos faz questionar até que ponto o discurso da civilização contra a barbárie transpôs o medo para justificar a própria selvageria, assim como os indígenas norte-americanos ficaram conhecidos por escalpelarem os seus inimigos; contudo, tratava-se de um mecanismo do Estado norte-americano para contabilizar o número de índios mortos..

Outro mecanismo utilizado e talvez um dos marcos deste processo expansionista do século XIX foi o dos grandes aldeamentos, iniciado em 1846, ano em que iniciam as políticas oficiais, com o estabelecimento do aldeamento de Nonoai, Votouro e Guarita no planalto sul-rio-grandense. Estes aldeamentos estavam interligados à política oficial do governo imperial e provincial e ao modo como estes órgãos entendiam a integração e a civilização dos indígenas. Ou seja, tirar-Ihes as possessões territoriais e introduzi-los em pequenos espaços de onde não poderiam sair.

\footnotetext{
Com a vinda dos colonos alemães (1824) e italianos (1875) era preciso que o índio fosse tirado do mato e reduzido a um território. Para este fim, são criadas as políticas indigenistas, características do século XIX, que propunham a organização de aldeamentos. Surgem, assim, o aldeamento de Nonoai no Alto Uruguai, de Campo do Meio e Colônia Militar Caseros no Mato Português, todos organizados pelo governo provincial para liberar as terras para a colonização (NONNENMACHER, 2000, p.24).
}

Nas décadas seguintes, houve uma série de problemas de desorganização de ordem administrativa e econômica em relação às terras, além da reação de algumas lideranças Kaingang e de suas parcialidades de se estabelecerem, ou não, nos aldeamentos. Sendo assim, os mecanismos apresentados, tais como, imigração alemã, companhias de pedestres e de bugreiros, abertura de estradas e aldeamentos corroboraram para o projeto colonizatório em que a frente de expansão do Estado Nacional brasileiro era representante. 


\section{Conflitos e alianças entre Kaingang e imigrantes alemães}

A formação dos aldeamentos está inserida no contexto da desocupação indígena Kaingang do planalto sul-rio-grandense, entre os quais territórios das Bacias Hidrográficas do Taquari-Antas e do Caí, a fim de que, por iniciativa do governo, fossem instalados nestas áreas, imigrantes alemães. O projeto imigratório na Província de São Pedro do Rio Grande do Sul sobrepunha-se aos espaços territoriais nos quais acontecia a manutenção socioeconômica dos Kaingang, uma vez que, para os Kaingang, este espaço era necessário para os cultivos, a caça e a pesca, como também para sua organização sociopolítica. Já por parte do Estado Nacional brasileiro, conforme referido, era necessária a desocupação destas terras para a valorização do território e o desenvolvimento do modo de produção liberal proposto pelo projeto imigratório. Instalado em territórios da porção norte da Bacia Hidrográfica do Caí, a partir da Colônia de São Leopoldo, o imigrante é visto como o portador das condições de "vida e de progresso" e capacitado a criar o ambiente necessário para o desenvolvimento da agricultura e do comércio nos moldes do capitalismo em expansão no qual os Kaingang não tinham lugar, pois "o índio aqui é o 'selvagem', o agressor; portanto, cabe ao poder público intervir no sentido de aldear o índio e defender o colono que é o gerador de riquezas" (NONNENMACHER, 2000, p.15).

Neste cenário, a partir de 1824, chegaram os imigrantes alemães ao Rio Grande do Sul. Atendendo ao projeto do Império Brasileiro, estabelecem-se a partir da antiga colônia de São Leopoldo em direção ao Caí, nos ditos espaços “vazios". Portanto, ao longo da década de 1820 a 1830, os imigrantes alemães passam a ocupar os tradicionais territórios Kaingang nas Bacias Hidrográficas do Caí e, posteriormente, territórios do Taquari-Antas, bem como, da encosta do planalto.

A concepção e o discurso acerca dos espaços ditos vazios, alicerçados no projeto de expansão territorial do Estado Nacional, designavam de forma pejorativa os Kaingang de "bugre" e "selvagem", visando assim deslegitimar o direito desses indígenas a seus territórios. Ainda, vale ressaltar que, muitas vezes, as pessoas que recebiam o benefício das terras concedidas nem sempre tinham boa índole. Conforme relato da viajante belga Maria van Langendonck ([1862] 2002) em seu diário, "[...] entre os colonos vindos da Alemanha, estavam ladrões, incendiários, assassinos. Quase todos eram indivíduos que haviam passado de quatro a doze anos na cadeia e com os quais tínhamos medo de nos encontrar nas florestas" (LANGENDONCK, [1862] 2002, p.57).

A imigração alemã estava na vanguarda da frente de expansão patrocinada pelo estado brasileiro, colocando em contato diferentes concepções culturais de etnias que deviam ocupar o mesmo território. De um lado, a etnia Kaingang buscava resguardar o território da presença de intrusos; de outro, os imigrantes buscavam garantir um direito enquanto colonos, que o Estado Brasileiro Ihes havia garantido. É possível imaginar as estranhezas geradas, de ambos os lados, entre colonos alemães e Kaingang, visto que se tratava de culturas distintas. Chamou a atenção de Becker (2006), em relação ao século XVIII e XIX e aos diferentes impactos sobre os Kaingang nestes dois contextos que:

a Colonização luso-espanhola efetiva não trouxe para os Kaingang as mesmas dificuldades que a alemã. Com os espanhóis, de modo particular, 


\begin{abstract}
a área Kaingang periférica sofre a ação indireta da política missioneira que se instalara desde inícios do século XVII com os Guarani, obtendo ótimos resultados. [...] Essa modalidade de colonização lusa permitiu a sobrevivência independente do índio e do português de forma que o Kaingang, coletor de pinhão, ficou nas áreas de mato e o criador luso na de campos. A seguir se multiplicam os municípios e, de modo especial, nas áreas de colonização alemã como se verá adiante. [...] A Colonização alemã, por sua vez, agiu mais direta, intensa e drasticamente sobre a área Kaingang desde 1824 a 1846 e de 1848 a 1874 . No primeiro momento, surgem as chamadas antigas colônias de São Leopoldo, São José do Hortêncio, Feliz, Mundo Novo, Bom Princípio e Pinhal, quando a área inicial de colonização se estende da Antiga Feitoria (São Leopoldo) até a borda do Planalto. Nessa época, antes mesmo dos colonos chegarem aos lotes destinados tinham de passar às vezes por terras dos índios que se defendiam à sua maneira. Desde 1829 a 1832 se repetem os encontros com colonos alemães estabelecidos em Dois Irmãos e de 1845 a $1847 \mathrm{com}$ os colonos de São Francisco de Paula e Nova Petrópolis (BECKER, 2006, p.128129).
\end{abstract}

Desta forma, nos espaços considerados vazios, tratando-se de territórios Kaingang, aconteciam os encontros entre estes e os imigrantes alemães, que é o que se entende por zonas de fronteiras étnicas. Segundo Barth ([1969] 2000), a fronteira étnica trata de um espaço que transpassa as fronteiras geográficas estabelecidas pelos estados nacionais. É o espaço onde as práticas sociais de diferentes culturas se encontram.

No caso dos territórios localizados nas bacias hidrográficas do Caí e do Taquari-Antas no século XIX, representam uma zona de fronteira interétnica entre imigrantes alemães e indígenas Kaingang. Ou seja, as relações entre os diferentes grupos se sucedem de maneira isolada das regras estabelecidas pelo governo e intensificam-se as práticas culturais, que resultam em conflitos ou mesmo em alianças entre ambos os grupos, como é possível visualizar no mapa (Figura 2). 
Figura 2 - Mapa indicando localidades de conflitos e alianças entre os Kaingang e mecanismos da frente de expansão no século XIX.

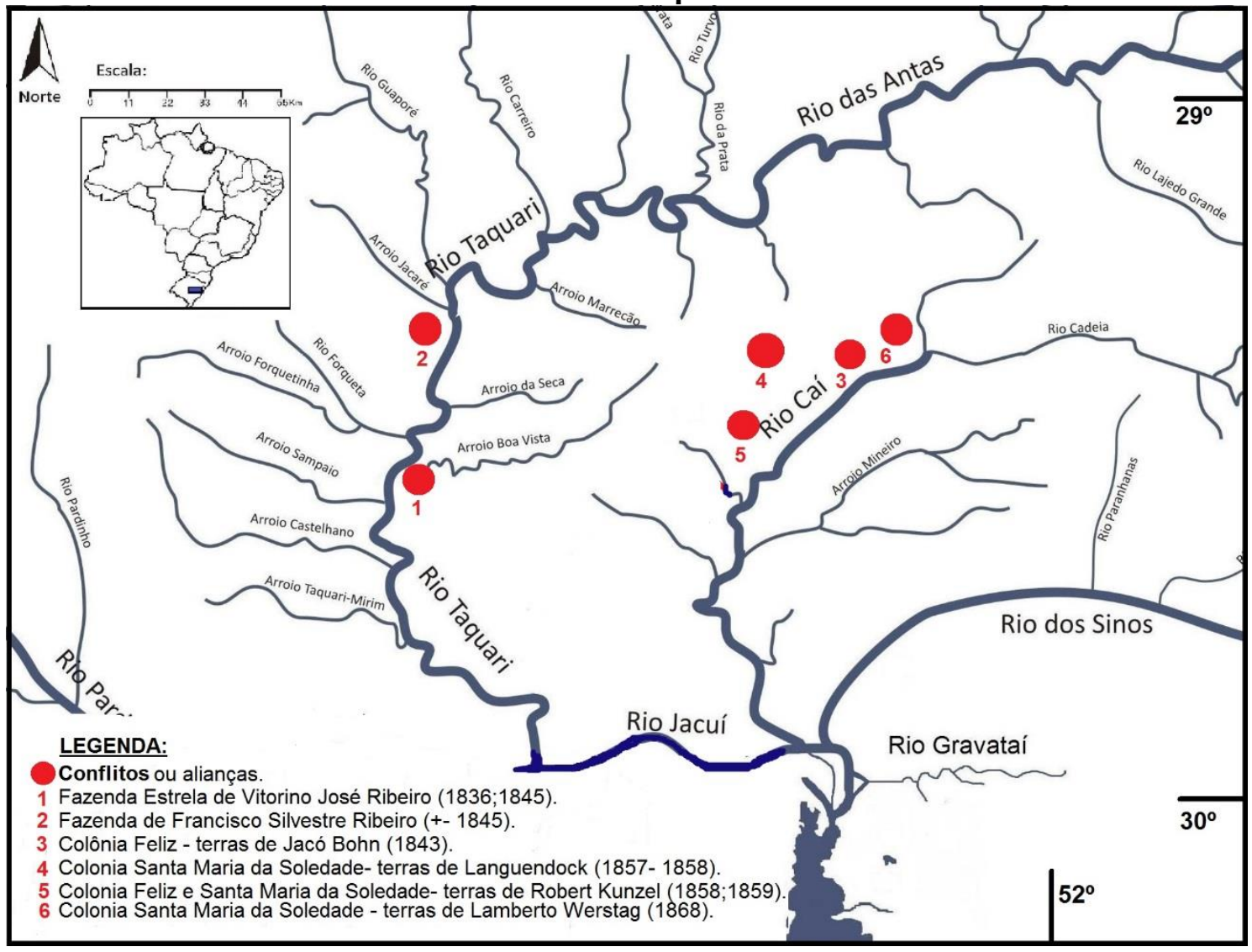

Fonte: Elaboração do autor.

A intensificação dos conflitos em territórios da Bacia Hidrográfica do TaquariAntas é concomitante ao avanço da imigração alemã rumo ao planalto e à perseguição a lideranças Kaingang como Doble, Braga e Nicué, o que leva à possibilidade de estes conflitos guerreiros terem sido orquestrados por algumas destas lideranças, para aumentar os limites territoriais onde elas atuavam, conforme aparece no mapa (Figura 3). 
Figura 3 - Mapa das movimentações de lideranças Kaingang em territórios entre os rios Sinos, Caí e Taquari-Antas.

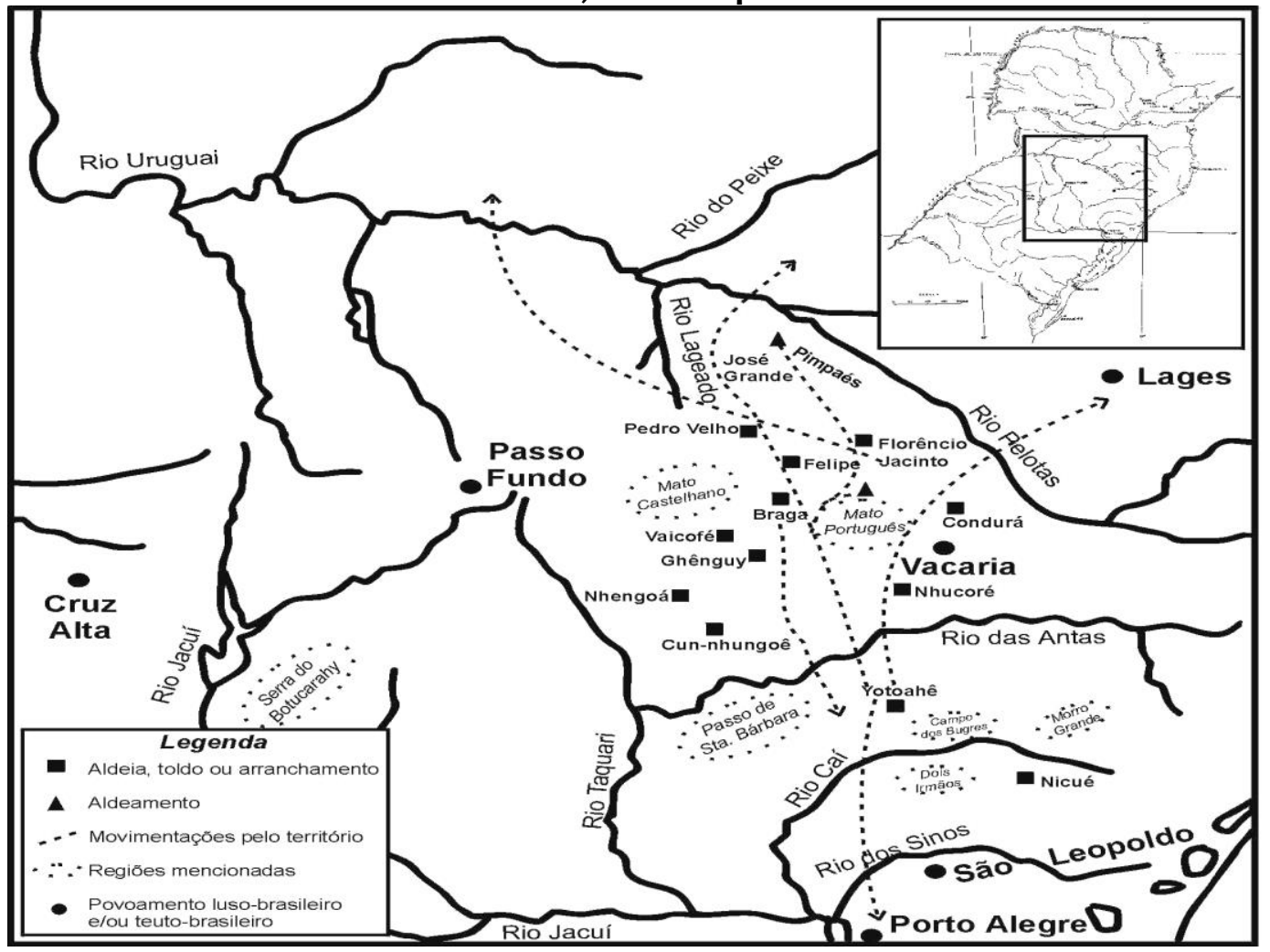

Fonte: Laroque (2000, p.151).

O consequente choque cultural foi inevitável, gerando frequentes conflitos de ambos os lados, principalmente, por parte dos Kaingang e as famílias de imigrantes alemães, como é caso de correrias indígenas às famílias Bohn, Kunzel e Wersteg, visto que os Kaingang eram os principais prejudicados com a redução de seu território. Cabe salientar que, se, por um lado, os conflitos em que indígenas foram os protagonistas estão bem documentados, por outro lado, os conflitos em que os imigrantes tomaram a iniciativa ou mesmo das companhias de extermínio do governo, não há, ou são poucos os registros documentados.

Alguns registros encontrados em ofícios e correspondências em arquivos do Rio Grande do Sul, bem como, em pesquisas recentes que se debruçam sobre a história indígena apontam que os conflitos começaram logo no início da imigração. Já no ano de 1829, há o registro de um conflito na Picada Dois Irmãos, pertencente à Colônia de São Leopoldo, localizada na Bacia Hidrográfica dos Sinos: "A partir de 1829 , foram registrados os primeiros ataques dos índios Coroados às colônias alemãs. Em 26 de fevereiro daquele ano, na Picada dos Dois Irmãos, pertencente à colônia sede São Leopoldo" (DORNELLES, 2011, p. 246).

Estes primeiros conflitos protagonizados pelos Kaingang nos entornos da Colônia de São Leopoldo são semelhantes aos registrados nos territórios da Bacia Hidrográfica do Taquari-Antas. Como exemplo, apontam-se os "assaltos", conforme denominação dos colonos, em "1834 e 1835, no Campo Novo, localizado na primeira légua de São Leopoldo, ironicamente conhecido como "Mortandades", onde, em 1835, morreram oito e ficaram feridos três colonos" (DORNELLES, 2011, p.246). 
No ano de 1843, há registro de conflito com os Kaingang à casa de Jacó Bohn à margem do Rio Caí, na colônia Feliz, conforme é possível visualizar no mapa (Figura 2). Segundo o registro do episódio na obra Gansweidt (1946), os colonos haviam revidado e teriam raptado um menino Kaingang de aproximadamente 11 anos a quem deram o nome Luís Antônio e, posteriormente, a alcunha pejorativa de Luís "Bugre”, que teria vivido boa parte de sua vida entre a colônia de Feliz e a mata, onde mantinha convívio com os Kaingang. Este menino, segundo a obra de Gansweidt (1946) e Dornelles (2011), viria a ser personagem central de um conflito no ano de 1868, na Colônia de Santa Maria da Soledade. Durante a década de 1870, atuou como guia nos deslocamentos dos imigrantes italianos pela mata até a localidade de Campos dos Brugres, onde, posteriormente, instalou-se o município de Caxias do Sul.

No decorrer da década de 1850, conforme Becker (1976), os registros apontam uma intensificação de conflitos em decorrência do avanço da frente de expansão em direção ao planalto e a consequente diminuição dos territórios Kaingang, além da pretensão de confiná-los em aldeamentos. O estudo de Pierre Clastres (2014), que analisa as sociedades primitivas do Paraguai e da Amazônia, descreve-as como sociedades da guerra/conflito pelo fato de gerar prestígio e equilíbrio entre os grupos, bem como, refere-se ao território que não tinha caráter de exclusividade e de dominação aos moldes do que ocorre com as sociedades quando o Estado está a presente. Percebe-se que a situação é semelhante ao que ocorre com os Kaingang. O território, nesse sentido, possui a função primordial de fazer com que sejam, ao mesmo tempo, totalidade e unidade coletiva.

A dimensão territorial já inclui o vínculo político na medida em que ela é a exclusão do Outro. É justamente o Outro - os grupos vizinhos - como espelho, que devolve à comunidade a imagem de sua unidade e de sua totalidade (CLASTRES, [1980] 2014, p.239).

Tomando Clastres ([1980], 2014) como referencial de análise para os dados em questão, reitera-se que é possível perceber que, na lógica cultural Kaingang, a concepção privada de território trazida pela frente de expansão por meio dos imigrantes alemães não fazia parte do seu modo de ser. Os indígenas Kaingang em estudo também desconheciam a fragmentação da unidade territorial, visto que, para eles, cultura e território é algo indivisível, ou seja, não é possível privar-se do uso do território em detrimento de um interesse privado.

A título de ilustração, no que diz respeito às incursões guerreiras indígenas, mencionamos os conflitos protagonizados pelos Kaingang, ocorridos em dezembro de 1858 e em março de 1859, conforme mapa (Figura 2). O primeiro terminou com a morte de um colono e o segundo com a morte de Robert Kunzel e de sua esposa. Cabe salientar que os registros, em grande parte, somente preocupam-se em contabilizar as mortes por parte dos colonos, enquanto as mortes Kaingang não aparecem registradas ou mensuradas na documentação, em função da invisibilidade dos indígenas por parte dos governantes da época e, posteriormente, até bem pouco tempo, pela própria historiografia. Os referidos episódios constam no relatório de 04 de março de 1860, escrito pelo diretor Carlos Gautner, da Colônia Santa Maria da Soledade, conforme segue: 
No mez Dezembro 1858 foi morto hum Colono de Picada Feliz, vizinho desta Colonia, a flecha, a casa do morto foi pilhada, apenas a mulher e as crianças puderão salvar a vida. No mez Março 1859 matarão na Colonia S. Maria de Soledade hum casal de Colonos, o Colono Robert Kunzel e a mulher dele, o mesmo habitava hum rancho aberto provisório na Colonia $\mathrm{N}^{\circ} 38$ Dst $^{\circ}$ Coelho [... ] (RELATÓRIO de 04/03/1860, AHRS).

$\mathrm{Na}$ análise deste documento, percebe-se que o relatório não apresenta os motivos do conflito; somente refere a forma violenta com que os Kaingang reagiram aos ocupantes da colônia, que, representando os interesses da frente de expansão, ocupavam o tradicional território indígena; portanto, os documentos somente apresentam uma das versões do acontecimento. Conforme Mabilde (1983, p. 184), "até certo ponto, não é a ambição que leva os coroados à guerra e sim, a maior parte das vezes, é a vingança que os guia". Este apontamento de Mabilde tem como base alguns registros de mortes entre os Kaingang por estarem espiando algumas propriedades, em 11 de dezembro de 1832 e em 27 de fevereiro de 1833, conforme segue:

o coroado que servia de espia foi morto pelo proprietário, conhecido pela alcunha de Manoel das Escadinhas, com um tiro de espingarda [...] $\mathrm{O}$ coroado deitou a fugir porém, embaraçando-se nas folhas e canas de milho que tinha atadas ao corpo, não pôde escapar, sendo morto com um tiro de pistola pelo capataz (MABILDE, 1983, p.188).

Conforme já abordado, vale lembrar que os imigrantes alemães foram largados à própria sorte em territórios já ocupados pelos Kaingang. E, por outro lado, aos Kaingang foi imposta a invasão do seu território e a coação da sua organização sociocultural, situação que intensificou suas incursões guerreiras nas colônias dos imigrantes alemães, conflitos intertribais com as parcialidades Kaingang inimigas, bem como, o deslocamento de grupos indígenas. Ou seja, o projeto imigratório como um dos mecanismos da frente expansionista desconsiderou completamente todo o cenário e a perspectiva de territorialidade Kaingang.

As notícias sobre conflitos envolvendo imigrantes alemães e indígenas Kaingang começavam a repercutir na Alemanha. Cunha (2006) analisa um documento de 1853, no qual o marine-director Kerst, numa conferência em Berlim, "opôs-se à imigração para o Rio Grande do Sul, afirmando que a colônia de Santa Cruz estava muito mal localizada e que seus habitantes estariam constantemente à mercê dos ataques indígenas" (CUNHA, 2006, p.288). Nesta colônia, em 1850, foi raptado o engenheiro Pierre Afonso Mabilde, que ficou sob domínio dos Kaingang por quase dois anos, o que resultou no relato referido anteriormente sobre sua experiência com o grupo. Especificamente sobre este suposto sequestro, presente nos apontamentos de Mabilde, inicialmente publicado em duas partes no Annuario do Estado do Rio Grande do Sul, respectivamente, em 1897 e 1899, e, posteriormente, como livro coordenado e revisado por suas bisnetas May Mabilde Lague e Eivlys Mabilde, publicado em 1983, D’Angelis (2006) levanta argumentos significativos questionando tal sequestro, bem como, a permanência por tanto tempo como prisioneiro entre os Kaingang. Um deles é que não existe nenhuma documentação referente ao sequestro, num período em que quase todos os ataques foram registrados; o outro argumento é as várias contradições existentes em tais apontamentos. Nesse sentido, 
também chama atenção ser insustentável que alguém, ocupando a posição de engenheiro agrimensor da Província, conforme é o caso de Mabilde, pudesse ter ficado prisioneiro de um grupo indígena por tanto tempo sem gerar uma reação do governo, sem estar registrado em correspondências ou, oficialmente, no relatório anual do Presidente de Província (D’Angelis, 2006).

Segundo Dornelles (2011), muitos conflitos ocorriam pelo fato de os Kaingang se sentirem no direito de se servirem das roças de milho dos colonos, que se encontravam prontas para a colheita; por isso, grande parte dos ataques ocorriam nos meses de dezembro e janeiro, no período de colheita. Ainda, conforme Clastres ([1980] 2014), as sociedades primitivas eram da abundância e do lazer. Ou seja, analisando as informações deste autor acerca dos acontecimentos Kaingang no século XIX, percebe-se que até o momento do contato com o colono, a subsistência não parecia ser um problema, salvo em períodos de guerra e/ou em função de condições climáticas que prejudicavam a obtenção da caça e da coleta, tanta era a abundância dos recursos naturais, que, paulatinamente, foram tomados pelos imigrantes alemães através do estabelecimento de colônias. Do ponto de vista Kaingang, servir-se das roças dos colonos, pelo fato de terem sido feitas em áreas de coleta e de caça no tradicional território, não deixa de ser o que sempre fizeram. $O$ relatório do conflito ocorrido no rancho do colono Robert Kunzel na colônia Feliz é ilustrativo nesse sentido:

a roça onde está o rancho estão plantado de milho, e esta rodeava o rancho, de maneira que os malfeitores puderão aproximar-se sem ser vistos a 10 passos do rancho (RELATÓRIO de 04/03/1860, AHRS).

Nesse contexto, também ocorreu o conflito protagonizado pelos Kaingang à colônia da família Wersteg, em dezembro de 1868, ocasião em que os dois filhos e a esposa de Lamberto Wersteg foram raptados numa das incursões dos Kaingang nos entornos do Arroio Forromeco, conforme mapa (Figura 2). A obra de Gansweidt (1946) e o relatório de Província de 13 de abril de 1868 descrevem o ataque ocorrido no dia 14 de janeiro de 1868 , conforme segue:

no dia 14 assaltarão os bugres a casa do colono Lambertus Wersteg, da Colonia Sta. Maria da Soledade, sita no $5^{\circ}$ Distrito do termo de São Leopoldo, levando para as mattas a família do mesmo Colono, composta de mulher e filho (RELATÓRIO de 13/04/1868, p. 30, AHRS).

O território deste episódio ficava na porção norte da Bacia Hidrográfica do Caí. Já o conflito mencionado anteriormente ocorre no limiar da fronteira étnica, representando o avanço da frente de expansão e as situações de contato entre Kaingang e alemães. Entende-se como frente de expansão, conforme Martins (1997), com base em seus estudos na região amazônica no século XX, o avanço inicial do capital e de sua expansão territorial. Logo, uma crítica à análise tradicional com visão desbravadora, substituindo-a por uma análise sociológica do contato para entender as singularidades das zonas de fronteira. No entender de Martins (1997), o cenário deste contato é caracterizado pela violência, ou seja, pela fricção e pela exploração no limiar de ambas as fronteiras, caracterizadas pelos conflitos. 
Recorrendo a Geertz (1978), entendemos que estas ações, bem como, seus significados foram orquestrados conforme a lógica cultural Kaingang, tanto no que diz respeito ao entendimento do uso coletivo e privado do território quanto no que diz respeito aos decorrentes conflitos. Tratando-se desta situação temos:

\begin{abstract}
os assaltos, retratados pelos colonizadores brancos, parecem violentações ou injustiças praticadas pelos índios; olhados pelos índios, no mínimo podem ser interpretados como atos de defesa ou vingança contra a invasão e opressão branca (BECKER, 1976, p.69).
\end{abstract}

Salienta-se que, a partir da segunda metade do século XIX, os Kaingang passam a usar outra estratégia em relação aos mecanismos da frente de expansão: as alianças com os chefes da Província ou mesmo com os moradores das colônias. Esta característica das alianças é tratada por Laroque (2000) como um dos elementos do colaboracionismo Kaingang. Isto é, de acordo com os interesses do grupo ao qual pertencia a liderança, estabeleciam-se, ou não, as alianças, uma vez que estes grupos viviam com seus conflitos internos, isto é, os conflitos entre as diferentes parcialidades Kaingang, o que possibilitava alianças com os chamados fóg (brancos), como, por exemplo, é o caso de atuações das lideranças Kaingang Braga, Doble e Nicué.

Esta situação de alianças fica visível em narrativas da viajante belga Madame van Langendonck ([1862] 2002), que refere em seus diários, o auxílio mútuo entre ela e uma família Kaingang, que havia se estabelecido nas proximidades de suas terras, prestando auxílio na abertura de estradas na Colônia Santa Maria da Soledade. Relata também que ela buscou auxílio com a família indígena em virtude dos perigos da floresta e em função de uma enfermidade que ela tinha. Há, ainda, referência a Luís "Bugre", o Luís Antonio, que, quando menino, tinha sido levado para o convívio com os brancos.

O guia que veio buscar-nos no dia seguinte era um ex-selvagem. Permanecera até a idade de dezesseis anos na tribo onde nascera. Ignoro que circunstâncias o haviam quase civilizado. Ele se colocara a serviço da Sociedade, sem ocupação especial, pois um trabalho regular lhe era singularmente antipático. Comumente ocupavam-no na caça ao tigre, pagando pela pele doze a dezoito francos (LANGENDONCK, [1862] 2002 p.45).

Outro exemplo de aliança por parte dos Kaingang ocorre em 1854, entre a liderança Doble e os funcionários do Presidente da Província. Isto ocorreu quando a referida liderança participou do resgate da família Waterpuhl na colônia do Mundo Novo, levando à morte a liderança Nicué.

Nesse episódio também foi solicitada a colaboração de Yotoahê (Doble) para resgatar os prisioneiros, o qual, mesmo tendo uma de suas filhas casada com um dos guerreiros de Nicué, certamente atendendo à lógica das negociações estipuladas por sua tribo, aceitou a missão. O desfecho final da trama após as informações recebidas por Maria, que depois, de quase um ano, conseguiu fugir do cativeiro Kaingang, foi uma emboscada de surpresa realizada pelo chefe Yotoahê e o Capitão Francisco Müller ao pessoal de Nicué (LAROQUE, 2000, p.143). 
Os dados arrolados nos possibilitam visualizar que estas alianças eram propostas a partir dos interesses que determinada parcialidade Kaingang poderia ter. Em nosso entender, as ações orquestradas tanto por parte dos Kaingang como por parte dos imigrantes tinham significados próprios para cada um dos grupos. Segundo Brandão (1986), as etnias tendem a atribuir significados simbólicos específicos para os eventos, situação que nas relações entre indígenas e colonizadores, muitas vezes, acarretou incompreensão e, consequentemente, conflitos.

\section{Considerações Finais}

Considera-se que o território localizado entre a Bacia Hidrográfica do Caí e a bacia hidrográfica do Taquari-Antas teve concepções distintas, o que foi um fator determinante na relação entre indígenas Kaingang e imigrantes alemães, tanto no âmbito dos conflitos como das movimentações. Por tratar-se de um espaço de disputa entre as duas etnias, a gradual perda do território fez com que os Kaingang, seguindo a lógica cultural indígena, intensificassem suas movimentações e investidas guerreiras contra os imigrantes alemães, que se estabeleciam nos territórios em análise, seguindo as orientações do Governo da Província de São Pedro do Rio Grande do Sul.

Vale enfatizar que o que diferenciava os Kaingang do imigrante eram seus valores simbólicos e padrões comportamentais relevantes para a identidade dos indivíduos em relação ao território. Neste trabalho, buscou-se apresentar o movimento das colônias ao longo da Bacia Hidrográfica do Caí, o qual provocou o contato interétnico entre imigrantes alemães e indígenas Kaingang. Evidencia-se que a colonização alemã estava inserida num processo instável de consolidação do Império e de modernização do Brasil no século XIX, no qual o Kaingang, detentor destes territórios, não era considerado. Também foram analisados movimentos da Frente de Expansão, em aspectos como a transferência da responsabilidade pela colonização do Império para as províncias, no caso, a do Rio Grande do Sul, e o aceleramento deste processo com a instalação das colônias particulares em meio ao contexto da Lei de Terras de 1850. Salienta-se que este movimento em direção ao planalto estava inserido no avanço da frente de expansão do Estado Nacional brasileiro, destacando-se outros mecanismos, como a abertura de estradas, companhias de pedestres e de bugreiros, bem como, os grandes aldeamentos, cujo objetivo era retirar os Kaingang do seu território, situação que nunca foi atingida em sua totalidade, tanto no que se refere ao século XIX quanto nos séculos XX e XXI, considerando que as viagens de ida e volta dos Kaingang nos territórios em questão ainda se mantêm.

\section{REFERÊNCIAS}

BARTH, F. Os grupos étnicos e suas fronteiras. IN: BARTH, Frederik. LASK, Tomke (org.). $O$ Guru, o iniciador e outras variações antropológicas. Tradução de John Cunha Comerford Rio de Janeiro: Contracapa, ([1969])2000. p. 25-67. 
BECKER, Í. I. B.. O índio kaingáng e a colonização alemã. In: SIMPOSIO DE HISTORIA DA IMIGRAÇÃO E COLONIZAÇÃO ALEMÃ NO RIO GRANDE DO SUL, 2, 196. São Leopoldo. Anais. São Leopoldo: Rotermund, 1976, p.45-71.

. O índio Kaingáng no Rio Grande do Sul. Pesquisas. Antropologia n² 29. São Leopoldo: Instituto Anchietano de Pesquisas/UNISINOS, 1976. [1976]1995.

O índio Kaingáng no Rio Grande do Sul. São Leopoldo: Ed. UNISINOS,

O que sobrou dos índios pré-históricos do Rio Grande do Sul. In: SCHMITZ, P. I. (org). Arqueologia do Rio Grande do Sul/Brasil. Documentos 5, 2. ed. Instituto Anchietano de Pesquisas, - UNISINOS São Leopoldo, RS, Brasil, p.125-148, 2006.

BRANDÃO, C. R. Identidade e Etnia. São Paulo: Ed. brasiliense, 1986.

BRINGMANN, S. F. Índios, colonos e fazendeiros: Conflitos interculturais e resistência Kaingang nas Terras Altas do Rio Grande do Sul. 2010. 217 f. Dissertação (Mestrado no Programa de Pós Graduação em História) - Universidade Federal de Santa Catarina, Florianópolis, dez. 2010.

BUBLITZ, J. Forasteiros na floresta subtropical: notas para uma história ambiental da colonização alemã no Rio Grande do Sul. Ambiente e Sociedade, Campinas, v. XI, n.2, p. 323-340. jul-dez. 2008.

CAVALCANTE, T. L. V. Etno-história e história indígena: questões sobre conceitos, métodos e relevância da Pesquisa. História (São Paulo). v. 30, n.1, p. 349-371, jan./jun. 2011.

CLASTRES, P. Arqueologia da Violência - pesquisas de antropologia politica. São Paulo: Cosac Naify, ([1980] 2014).

CUNHA, J. L. Imigração e colonização alemã. In: BOEIRA, Nelson, GOLIN, Tau (Coords. Colônia (Coleção História Geral do Rio Grande do Sul). Passo Fundo: Méritos, v. 2. 2006. p. 279-300.

D’ANGELIS, W. Mabilde e seus “apontamentos" sobre os Coroados Selvagens: tentando separar informação de mistificação e preconceitos. Anais da $25^{\text {a }}$ Reunião Brasileira de Antropologia, Goiânia, 11 a 14 jun., 2006. Disponível em: http://www.ifch.unicamp.br/ihb/Textos/GT48Wilmar.pdf. Acesso em: 06 set. 2018. DORNELLES, S. S. A história em As vítimas do bugre, ou como tornar-se bugre na História. Anos 90, Porto Alegre, v. 18, n. 34, p. 245-278, dez. 2011.

FARINATTI, L. A. Confins Meridionais: famílias de elite e sociedade agrária na Fronteira Sul do Brasil (1825-1865). 2007. 421f. Dissertação (Programa de PósGraduação em História Social) - Universidade Federal do Rio de Janeiro, Rio de Janeiro, mar. 2007. 
GANSWEIDT, M. J. As vítimas do Bugre. Porto Alegre: Selbach, 1946.

GEERTZ, C. A Interpretação das Culturas. Rio de Janeiro: Zahar Editores, 1978.

GONÇALVES, C. A.; MEIRELLES, A. M. Projetos e relatórios de pesquisa em Administração. São Paulo: Atlas, 2004.

LANDO, A. M; BARROS, E. C. Capitalismo e Colonização - os alemães no Rio Grande do Sul. In: LANDO, A. M; DACANAL, J. H.; GONZAGA, S. (orgs.). RS: imigração e colonização. Porto Alegre: Mercado Aberto, 1996. p.9-33.

LANGENDONCK, M. van. Uma colônia no Brasil. Tradução de Paula Berinson e introdução de Augusto Meyer. Florianópolis: Editora Mulheres, [1862], 2002. LAROQUE, L. F. da S. Lideranças Kaingang no Brasil Meridional (1808-1889). Pesquisas. Antropologia $\mathbf{n}^{\circ}$ 56. São Leopoldo: Instituto Anchietano de Pesquisas/UNISINOS, 2000.

MABILDE, P. F.A. B. Apontamentos sobre os indígenas selvagens da Nação Coroados dos matos da Província do Rio Grande do Sul - 1836-1866. São Paulo, IBRASA, 1983.

MARTINS, J. de S. O tempo da fronteira retorno à controvérsia sobre o tempo histórico da frente de expansão e da frente pioneira. Tempos social; Rev. Sociol. São Paulo, USP. v.8, p.25-70, maio de 1996.

. Fronteira: a degradação do Outro nos confins do humano. São Paulo, Ed Hucitec, 1997.

MEZZAROBA, O.; MONTEIRO, C. S. Manual de metodologia da pesquisa no Direito. 3. ed. São Paulo: Saraiva, 2006.

NONNENMACHER, M. S. Aldeamento Kaingang no Rio Grande do Sul (século XIX). Porto Alegre: EDIPUCRS, 2000.

NÖTZOLD, A. L. V.; BRINGMANN, S. F. O que fazer com os bugres? Discurso sobre a civilização e catequese dos Kaingang no Rio Grande do Sul do século XIX. Revista Mnemonize, v. 1. n.2, jul/dez 2010. p.17-40.

RELATÓRIO de 04/03/1860 - Relatório do diretor Carlos Gautner da Colônia Santa Maria da Soledade ao Presidente da Província relatando os ataques indígenas a Colônia. AHRS, caixa 35, maço 66. Fundo colonização.

RELATÓRIO de 13/04/1968 - Relatório com que o Exmo. Sr. Dr. Francisco I. Marcondes Homem de Mello passou a administração d'desta Província ao Excelentíssimo Senhor Doutor Joaquim Vieira da Cunha, $1^{\circ}$ Vice-presidente. AHRS, Porto Alegre: Typographia do Jornal do Commercio, 1968, p. 30. 
ROCHE, J. A colonização alemã e o Rio Grande do Sul. v.1. Porto Alegre: Ed. Globo, 1969.

RODRIGUES, C. R. O nativo e o colono: o projeto de modernização do estado do Rio Grande do Sul. In: FERNANDES, E.; NEUMANN, R. M.; WEBER, R. (orgs.). Imigração: diálogos e novas abordagens. São Leopoldo: Oikos, p.61-75, 2012.

RÜCKERT, F. Q. A colonização alemã e italiana no Rio Grande do Sul: uma abordagem na perspectiva da História Comparada. Revista Brasileira de História \& Ciências Sociais. v. 5, n. 10, p.203-225. Dez. 2013.

SEYFERTH, G. Colonização, imigração e a questão racial no Brasil. Revista USP, São Paulo, n.53, p.117-149, mar./mai. 2002.

Luís Fernando da Silva Laroque. Doutor em História. Professor e pesquisador do Programa de Pós-Graduação em Ambiente e Desenvolvimento da Universidade do Vale do Taquari (Univates).Iflaroque@univates.br

Neli Teresinha Galarce Machado. Doutora em Arqueologia. Professora e pesquisadora do Programa de Pós-Graduação em Ambiente e Desenvolvimento da Universidade do Vale do Taquari (Univates).ngalarce@univates.br

Moisés Ilair Blum Vedoy. Graduação em História pela Univates. Mestrando no Programa de Pós-Graduação em Ambiente e Desenvolvimento da Universidade do Vale do Taquari (Univates) com bolsa PROSUC/CAPES. moisesvedoy@gmail.com 